\title{
Kerusakan Lamun (Seagrass) dan Rumusan Konservasinya di Tanjung Luar Lombok Timur
}

\author{
${ }^{1}$ Abdul Syukur, ${ }^{2}$ Yusli Wardiatno, ${ }^{2}$ Ismudi Muchsin dan \\ ${ }^{2}$ Mohammad Mukhlis Kamal. \\ 1) Program Studi Pendidikan Biologi Universitas Mataram \\ ${ }^{2)}$ Departemen Manajemen Sumberdaya Perairan, Fakultas Perikanan dan Ilmu \\ Kelautan Institut Pertanian Bogor.Jl. Agatis Kampus IPB Darmaga Bogor 16680 \\ *Corespondensi author e mail: syukur_unram@ymail.Com.go.id
}

\begin{abstract}
Abstraks
Lamun memiliki fungsi yang cukup vital di lingkungan laut. Fungsi vital lamun adalah habitat biota laut, produktivitas primer, mengatur tingkat trofik serta regulasi gas untuk keseimbangan gas $\mathrm{CO}_{2}$ dan $\mathrm{O}_{2}$ di atmosfir melalui mekanisme fotosintesis. Disisi lain laju kerusakan lamun terus terjadi dan sulit diprediksi akibat over-ekploitasi. Tujuan penelitian ini adalah untuk memahami implikasi ekologi dari over-ekploitasi terhadap degradasi biota yang bernilai ekonomi dan kerusakan akibat penggunaan alat yang tidak ramah lingkungan. Selanjutnya merumuskan indikator ekologi dari kedua parameter tersebut sebagai dasar konservasi lamun. Metode pengambilan data melalui survei, observasi, kuesioner dan dokumentasi. Survei untuk memahami karakter masyarakat yang dipilh sebagai responden dan observasi untuk penilaian jumlah biomassa lamun. Kuesioner untuk menilai kondisi biota yang bernilai ekonomi berdasarkan preperensi masyarakat dan dokumen adalah yang berkaitan dengan ikan hasil tangkapan nelayan, khususnya ikan baronang (Siganidae). Analisis data dilakukan secara diskriptif dan sintesis untuk merumuskan indikator ekologi sebagai dasar konservasi lamun. Hasil penelitian ini menunjukkan over-ekploitasi memiliki dampak yang cukup besar terhadap degradasi biota seperti ikan, moluska, kepiting, see-urchin dan tripang. Implikasi ekologinya dapat dilihat dari degradasi biota yang memiliki peran penting untuk menilai kualitas keanekaragaman hayati dan degradari populasi dari komponen penyususn tingkat trofik yaitu pada level herbivora dari jenis Siganidae dan see-urchin. Selanjutnya nilai biomassa lamun yang hilang akibat penggunaan alat yang tidak ramah lingkungan. Dari parameter kerusakan lamun dan implikasi ekologi dari degradasi biota digunakan sebagai dasar pertimbangan dalam rumusan konservasi lamun di lokasi studi.
\end{abstract}

Kata kunci: Over-ekploitasi, Kerusakan lamun dan Konservasi. 


\section{PENDAHULUAN}

Konservasi berdasarkan definisi dari the World Conservatioan Strategy berkaitan dengan dengan prinsip pemeliharaan proses ekologi dan keberlanjutan sistem pendukung kehidupan (Lavery et al 2001). Lamun memiliki fungsi secara fungsional dalam pemeliharaan proses ekologi untuk keberlanjutan biota laut dan dapat berperan sebagai penyedia barang dan jasa (goods and service) bagi kebutuhan manusia (Ronnback dan Torro-Castro 2004). Dari aspek lingkungan lamun berperan sebgai pondasi spesies (Waycott et al 2009). Hal ini dapat dibuktikan dari berbagai jenis hewan yang membuat tempat atau lubang (burrows) dan selanjutnya menjadi habitat spesies lain (Coleman dan Williams 2002), fungsi lamun yang cukup esensial di lingkungan laut adalah sebagai produktivitas primer dari proses fotosintesisnya (Willams et al. 2006). Selain itu lamun di lingkungan laut adalah habitat dan tempat mencari makan berbagai jenis hewan seperti invertebrata, ikan dan burung (Waycoot et al 2009). Oleh karena itu keberadaan lamun di lingkungan laut untuk keberlanjutan dari keragaman jenis ikan karang yang memanfaatkan lamun sebagai tempat mencari makan (Cullen dan Unsworth 2010).

Laju kerusakan lamun secara glabal tidak dapat diprediksi, namun dari penyebab kerusakan yang cukup dominan berasal dari aktivitas antropogenik (Tomascik et al 1997). Kerusakan lamun banyak disebabkan oleh perahu nelayan, aktivitas pembangunan serta meningkatnya jumlah penduduk yang tinggal di wilayah pesisir (Davis dan Fyfe 2007).
Sumber ancaman lamun yang telah menyebabkan degradasi lamun adalah meningkatnya laju pembangunan fisik seperti pembangunan pelabuhan, dermaga perikanan, pengembangan kawasan industri dan aktivitas pemanfaatan yang tidak ramah lingkungan (Dahuri 2003). Sumber lain dari ancaman kerusakan lamun berasal dari alam seperti badai, vulkanik dan pemanasan global (Neckless and Frederick 1999).

Lamun di areal studi mendapat gangguan yang cukup intensip dari aktivitas pemanfaatan oleh nelayan dan masyarakat non nelayan. Berdasarkan hasil studi REA (Resources Environmental Assessment) dari Co-Fish Project (2001) menyebutkan di Lombok Timur termasuk Tanjung Luar telah terjadi kerusakan ekosistem seperti mangrove seluas 331,7 ha, terumbu karang mencapai $45 \%$ dan lamun. Implikasi dari kerusakan ekosistem tersebut diasumsikan berpengaruh terhadap penurunan produksi ikan yang dihasilkan nelayan kecil (small scale). Salah satu jenis ikan ekonomi penting yang memiliki asosiasi kuat dengan lamun dan sebagai sasaran tangkapan nelayan adalah ikan baronang. Kondisi produksi ikan baronang di lakosi studi pada tahun 2005 sebesar 3,4 ton tahun 2005 dan turun menjadi 1,4 ton tahun 2009 (BPS, NTB, 2009).

Lamun yang memiliki peran cukup esensial untuk kelestarian biodiversity, saat ini mangalami proses degradasi akibat ever-ekploitasi seperti di lokasi studi. Disisi lain penelitian yang berkaitan dengan besarnya kerusakan lamun dan implikasi ekologi terhadap keragaman jenis biota yang berasosiasi dengan lamun seperti ikan 
dan biota lainnya belum menjadi pertimbangan utama dalam perlindungan dari konservasi pada tingkat nasional maupun daerah. Oleh karena itu solusi pundamental dan rasional untuk mencegah laju degradasi dan meningkatkan kualitas habitat lamun untuk mendukung fungsi ekologi yang esensial sebagai areal mencari makan (feeding grounds) dan pemeliharaan (nursery grounds) dan kelestarian biodiversity serta pengelolaaan sumberdaya perikanan yang berkelanjutan dalam jangka panjang adalah melalui konservasi atau perlindungan (Funnel et al 1999). Berkaitan dengan nilai-nilai konservasi dan kerusakan lamun di lokasi studi fokus penelitian ini adalah tentang degradsi lamun dan skala perlindungan atau konservasi lamun berdasarkan indikator ekologi.

\section{METODE PENELITIAN}

Lokasi penelitian terletak di wilayah pesisir Tanjung Luar Lombok Timur pada posisi geografis $116^{\circ} .37^{\prime}$ $116^{\circ} .45^{\prime}$ bujur timur dan $8^{\circ} 17^{\prime}-8^{\circ} 18^{\prime}$ lintang selatan. Penelitian ini di laksanakan pada bulan April sampai Agustus tahun 2010, di perairan Tanjung Luar Lombok Timur. Penelitian ini didesain berdasarkan pertama degradasi beberapa jenis biota yang memiliki nilai ekonomi akibat eksploitasi oleh nelayan dan masyarakat dan kedua besarnya nilai biomassa lamun yang rusak akibat pemanfaatan yang tidak ramah lingkungan oleh masyarakat non nelayan. Dari kedua indikator tersebut dirumuskan indikator ekologi sebagai dasar desaian konservasi lamun dan strategi pengelolaannya.
Data penelitian bersumber dari data primer dan data sekunder. Pengambilan data melalui observasi, survei, kuesioner dan dokumentasi dari jenis ikan hasil tangkapan nelayan kecil. Data primer yang berkaitan dengan degradasi biota yang bernilai ekonomi diperoleh melalui observasi yaitu untuk menentukan komposisi responden sesuai dengan jenis pekerjaan utamanya. Selanjutnya kuesioner pertama untuk memperoleh data tentang manfaat lamun bagi lingkungan dan ekonomi masyarakat lokal dan kedua untuk memperoleh data tentang kondisi dari beberapa jenis biota yang bernilai ekonomi yang berasosiasi dengan lamun. Data tentang biomassa lamun yang rusak akibat pemanfaatan yang tidak ramah lingkungan diperoleh melalui survei terhadap individu. Pada bagian ini data dikelompokkan pertama berdasarkan jenis alat yang digunakan yaitu pisau, sabit dan gareng dan kedua berdasarkan jenis lamunnya.

Sampel dari responden diambil secara proposional sesuai dengan karakter responden seperti nelayan kecil yang terdiri dari nelayan kecil umum, nelayan oros, nelayan ngerebus dan nelayan pencari udang dan masyarakat non nelayan. Wawancara mendalam dilakukan pada anggota masyarakat dapat menjadi sumber informasi utama (key respondents) yang meliputi tokoh adat dan pemerintah desa.

Analisis data berdasarkan hasil yang diperoleh dari jawaban responden dan produksi ikan hasil tangapan nelayan kecil dianalisis secara diskriptif. Hasil analisis ini dapat menggambarkan tentang implikasi kerusakan lamun terhadap degradasi biota yang 


\begin{abstract}
berdampak pada kelestarian keanekaragaman hayati (biodiversity) dan degradasi komposisi level trofik dari kelompok herbivora. Selanjutnya analisis biomassa lamun akibat pemanfaatan yang tidak ramah lingkungan dengan menggunakan formula: $\mathrm{B}=\mathrm{W} / \mathrm{A}$

Dimana:

$\mathrm{B}=$ Biomassa lamun jenis ke-i (gram basah/orang dan jenis alat)

$\mathrm{W}=$ Jumlah total berat basah jenis ke-i (gram basah)

A = Individu (orang dan alat)

Hasil analisis dari parameter di atas selanjutnya dilakukan sintesis. Indikator ekologi dari hasil penilaian responden tentang kondisi sumberdaya yang bernilai ekonomi, manfaat lamun bagi lingkungan serta manfaat lamun bagi ekonomi masyarakat bersifat subjektip, sedangkan indikator ekologi yang dari penilaian biomassa lamun bersifat mutlak (Lavery et al 2001). Indikator ekologi yang diperoleh dapat disebut sebagai indikator ekologi yang signifikan sebagai rumusan desaian konservasi lamun dan strategi pengelolaanya.
\end{abstract}

\section{HASIL DAN PEMBAHASAN}

\section{Potensi Ancaman lamun (Seagrass)}

\section{1.Nelayan kecil}

Nelayan kecil (small fisheries) di wilayah studi dari jumlah armada penangkapan berjumlah $84,33 \%$ dari total nelayan sebesar 1.143 dan sebagai nelayan penangkap sebesar $69,78 \%$ dari jumlah profesi nelayan sebesar 5276 orang. Komposisi nelayan yang cukup besar tersebut menjadi ancaman serius terhadap lamun dan ekosistemnya. Hal ini dapat dipahami karena areal lamun adalah pilihan utama ikan yang bernilai ekonomi untuk bermigrasi dari habitat aslinya ke padang lamun baik untuk mencari makan dan berlindung dari predator.

Jenis ikan tersebut yang dapat menjadi indikator tangkapan nelayan dari padang lamun adalah Siganidae (Unsworth et al 2007). Spesies lain yang menjadi indikator dari hasil tangkapan nelayan di padang lamun dilaporkan oleh Mangi dan Roberts (2007) adalah jenis ikan dari Lethrinidae (emperors), Scaridae (parrotfish), Siganidae (rabbitfish) dan Mullidae (goadfish). Selanjutnya Unsworth et al (2008) menyatakan jenis ikan yang masih pada massa juvenil (small juvenil) dari jenis Siganidae dan Lethrinids cukup dominan ditangkap oleh nelayan pada areal lamun di perairan Indo-Pasifik.

Keragaman jenis ikan yang bernilai ekonomi di areal padang lamun adalah sebagai salah satu faktor dari nelayan di lokasi studi menjadikan areal lamun sebagai areal tangkpan. Jumlah nelayan yang cukup besar tentu berimplikasi terhadap over-exploitasi dengan pengguanaan alat tangkap yang memiliki kecendrungan merusak lamun. Nelayan di lokasi studi yang mengguankan padang lamun sebagai areal tangkapan terdiri dari: (1) nelayan kecil umum, (2) nelayan oros dan (3) nelayan penangkap udang dan rajungan. Dari ketiga kelompok nelayan tersebut yang dominan menggunakan areal lamun sebagai areal tangkapan adalah nelayan oros. Secara rinci dari ketiga kelompok nelayan tersebut seperti pada (Tabel 1) 
Tabel 1. Komposisi Nelayan Berdasarkan Areal Tangkapan dan Hasil Tangkapan.

\begin{tabular}{|c|c|c|c|}
\hline No & Kelompok Nelyan & Areal Tangkapan & Hasil Utama Tangkapan \\
\hline 1 & Nelayan kecil umum & $\begin{array}{l}\text { Perairan umum, padang } \\
\text { lamun dan estuarin }\end{array}$ & $\begin{array}{l}\text { Jenis ikan yang } \\
\text { konsumsi }\end{array}$ \\
\hline 2 & Nelayan oros & Padang lamun dan estuarin & $\begin{array}{l}\text { Semua jenis yang } \\
\text { konsumsi dan tidak bernilai } \\
\text { konsumsi }\end{array}$ \\
\hline 3 & $\begin{array}{l}\text { Nelayan penangkap } \\
\text { udang dan rajungan }\end{array}$ & $\begin{array}{l}\text { Padang lamun, esturin dan } \\
\text { sekitar terumbu karanag }\end{array}$ & Udang dan rajungan \\
\hline
\end{tabular}

Nelayan (Tabel 1), khusus pada nelayan kecil umum di dalamnya ada kelompok nelayan yang disebut sebagai nelayan "ngerebus". Nelayan jenis ini menggunakan troll mini dan menangkap ikan di areal padang lamun. Jenis ikan yang menjadi sasaran tangkapan adalah Carangidae, Haemullidae, Scraridae, Siganidae, Mugilidae dan Lethrinidae. Nelayan oros juga menggunakan troll mini dan ini paling dominan manangkap ikan di areal padang lamun. Jenis ikan sebagai sasaran tangkapan mereka adalah Siganidae, Monacanthidae dan Leiognathidae. Selanjutnya nelayan penangkap udang dan rajungan (prawns dan crabs). Kelompok nelayan ini terdiri dari dua yaitu kelompok penangkap udang kecil sebagai bahan baku pembuatan terasi dan kelompok penangkap udang besar dan kepiting. Jenis kepiting yang cukup dominan diperoleh adalah jenis Portunas pelagicus dan Portunus sanguinolentus. Kedua jenis kepiting tersebut dalam bahasa lokal di daerah studi disebut "sure".
Pemanfaatan areal lamun oleh kelompok nelayan yang disebutkan di atas adalah bentuk over-ekploitasi sumberdaya lamun. Thomascik et al (1997) menjelaskan kerusakan lamun disebabkan oleh over-ekploitasi nelayan. Selanjutanya hasil identifikasi dari responden tempat ikan berkumpul dan sebagai areal tangkapan nelayan seperti pada (Gambar 1). Hasil analisis menunjukkan terumbu karang dan padang lamun merupakan habitat yang sangat penting bagai ikan. Kondisi tersebut dapat menjadi dapat menjadi dasar untuk menyatakan bahwa lamun mendapat tekanan yang cukup serius. Kerusakan lamun akibat over-ekploitasi ikan dari jenis Siganidae terjai ditempat lain seperti di Teluk Banten (Thomascik et al (1997) dan Exton (2010) in Cullen dan Unsworth (2010) menyatakan overekploitasi telah berdampak pada penurunan hasil produksi ikan dari padang lamun di perairan Indonesia lebih dari 5 tahun. 


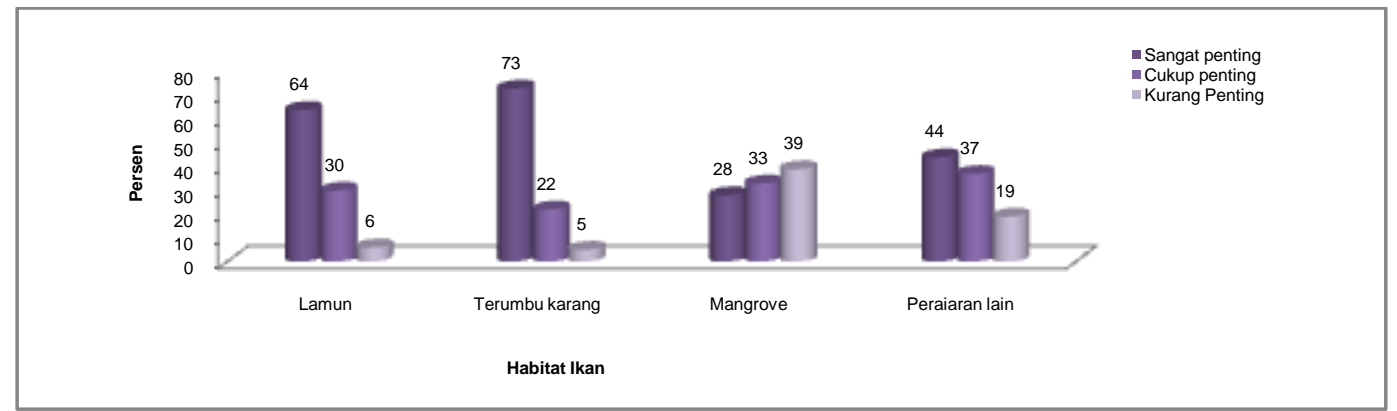

Gambar 1. Habitat Ikan Menurut Nelayan Umum di Wilayah Studi $(\mathrm{n}=60)$

\subsection{Masyarakat non nelayan}

Areal padang lamun di lokasi studi tidak hanya menarik bagi nelayan, masyarakat non nelayan cukup intensip memanfaatkan areal padang lamun. Hal ini dapat dipahami karena areal padang lamun merupakan habitat dari biota yang bernilai ekonomi seperti moluska, tripang, see-urchin dan lain-lain. Hasil identifikasi masyarakat non nelayan yang memanfaatkan areal lamun terdiri dari: (1) kelompok atau individu dengan tujuan mencari moluska, see-urchin buah dan yang lainnya, (2) kelompok atau individu yang bertujuan mencari ikan dan yang lainnya dan (3) pembudiaya keramba apung yang bertujuan mencari jenis tripang sebagai pakan udang. Dari hasil observasi pada saat penelitian jumlah masyarakat non nelayan yang memanfaatkan areal padang lamun di lokasi studi seperti pada (Tabel 2).

Tabel 2. Komposisi dan kisaran Jumlah Masyarakat Non Nelayan yang Memanfaatkan Areal Padang Lamun Setiap Hari pada Saat Air Surut.

\begin{tabular}{llcccl}
\hline No & Lokasi & \multicolumn{3}{c}{ Kelompok Masyarakat dan Kisaran } & Alat dan bahan yang digunakan \\
& & \multicolumn{3}{c}{ Jumlah orang/Hari } \\
& & 1 & 2 & 3 & \\
\hline 1 & Gili kere & $150-200$ & $50-70$ & - & Gareng, sabit, pisau dan potasium \\
2 & Poton Bakau & $250-370$ & $20-45$ & $30-45$ & Gareng, sabit, pisau dan potasium \\
3 & Lungkak & $50-75$ & - & - & Gareng, sabit dan pisau \\
4 & Kampung Baru & $25-60$ & - & - & Gareng, sabit dan pisau \\
\hline
\end{tabular}

Keterangan : $\quad-\quad=$ tidak ditemukan anggota masyarakat non nelayan

1 = Kelompok masyarakat yang bertujuan mencari see-urchin, moluska, buah lamun dan lain-lain

2 = Kelompok masyarakat yang mencari ikan dengan menggunakan Potasium

3 = Pembudidaya udang

Over-exploitasi adalah ancaman yang dapat berdampak pada kerusakan lamun. Implikasi ekologi dari overekploitasi tersebut dapat dijelaskan pertama yang berkaitan dengankeanekaragaman hayati (Biodiversity). keanekaragaman biota yang berasosiasi dengan lamun dapat dilakukan sesuai konsep keanekaragaman. Konsep keanekaragaman dapat menggambarkan tentang kekayaan jenis atau spesies pada suatu areal atau lokasi seperti di padang lamun. Selanjutnya nilai keanekaragaman ditentukan oleh jumlah 
spesies dan jumlah individu tiap spesies. Berkaitan dengan parameter yang memiliki keterkaitan dengan nilai keanekaragaman pada penelitian ini dilakukan penilaian berdasarkan

preperesensi masyarakat terhadap kondisi dari beberapa jenis biota yang umum diperoleh dari padang lamun. Hasil penilaian responden seperti pada (Gambar 2).

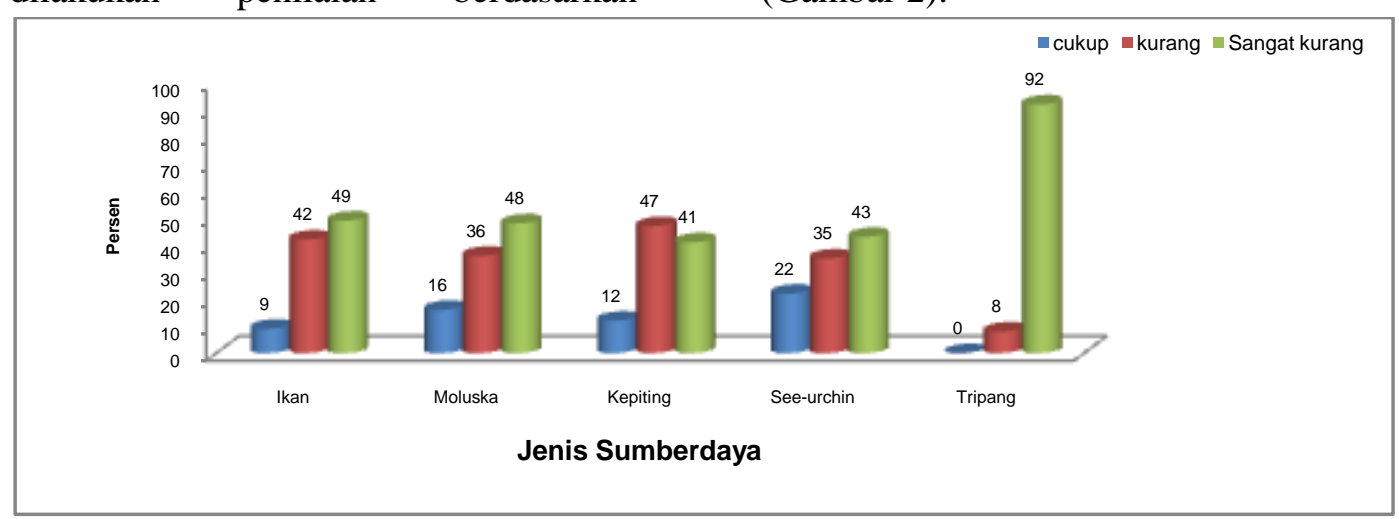

Gambar 2. Kondisi Lima Jenis Biota Hasil Penilaian Responden, $\mathrm{n}=50$

\section{Hasil penilaian responden}

(Gambar 2) dapat menjelaskan bahwa implikasi dari over-ekploitasi, khususnya kelima jenis biota tersebut dari jumlah populasinya berada dalam kondisi yang sangat menghawatirkan atau berbahaya dan bahkan untuk jenis tripang sudah sangat langka karena dari 50 responden tidak ada yang menyatakan cukup dan hanya $8 \%$ yang menyatakan kurang dan sisanya menyatakan sangat kurang. Kondisi ini tentu akan mengancam kelestarian biodiversity sebagai fungsi lamun dalam menyediakan habitat untuk keragaman jenis biota untuk survive.

Degradasai jumlah biota tersebut secara langsung dapat mempengaruhi nilai keanekaragaman jenis biota pada padang lamun di lokasi studi. Hal ini dapat dijelaskan karena tinggi rendahnya nilai keanekaragaman hayati ditentukan oleh pertama jumlah jenis atau spesies, kedua akibat dari rendahnya anggota populasi tersebut akan ada jenis yang cukup dominan dan ketiga keragamann jenis biota yang berasosiasi dengan lamun bersifat homogen. Konsep keanekaragaman selain dapat menggambarkan kekayaan jenis dapat juga digunakan untuk membuat keputusan tentang strategi pengelolaan yang berbasis konservasi ekosistem (Griffiths 2001). Selanjutnya Nemeth $e t$ al (2007) menjelaskan asosiasi beberapa jenis biota dengan lamun dapat menjadi alat untuk melakukan monitoring dan evaluasi tentang komposisi jenis biota dan nilai keanekaragaman.

Over-ekploitasi secara langsung berdampak terhadap menurunnya kualitas fungsi lamun untuk keberlanjutan keragaman jenis biota yang berasosiasi dengan lamun di lokasi studi. Dalam hal ini Norse (1993) dalam Larkum et al (2006) menyebutkan ancaman serius dari kerusakan lamun berasal dari exsploitasi yang melebihi kemampuan pulih. Namun demikian informasi tentang sumber kerusakan lamun merupakan bagian yang sangat penting sebagai dasar pertimbangan dalam konservasi dan pengelolaan yang berkelanjutan (Coles et al 2008). 


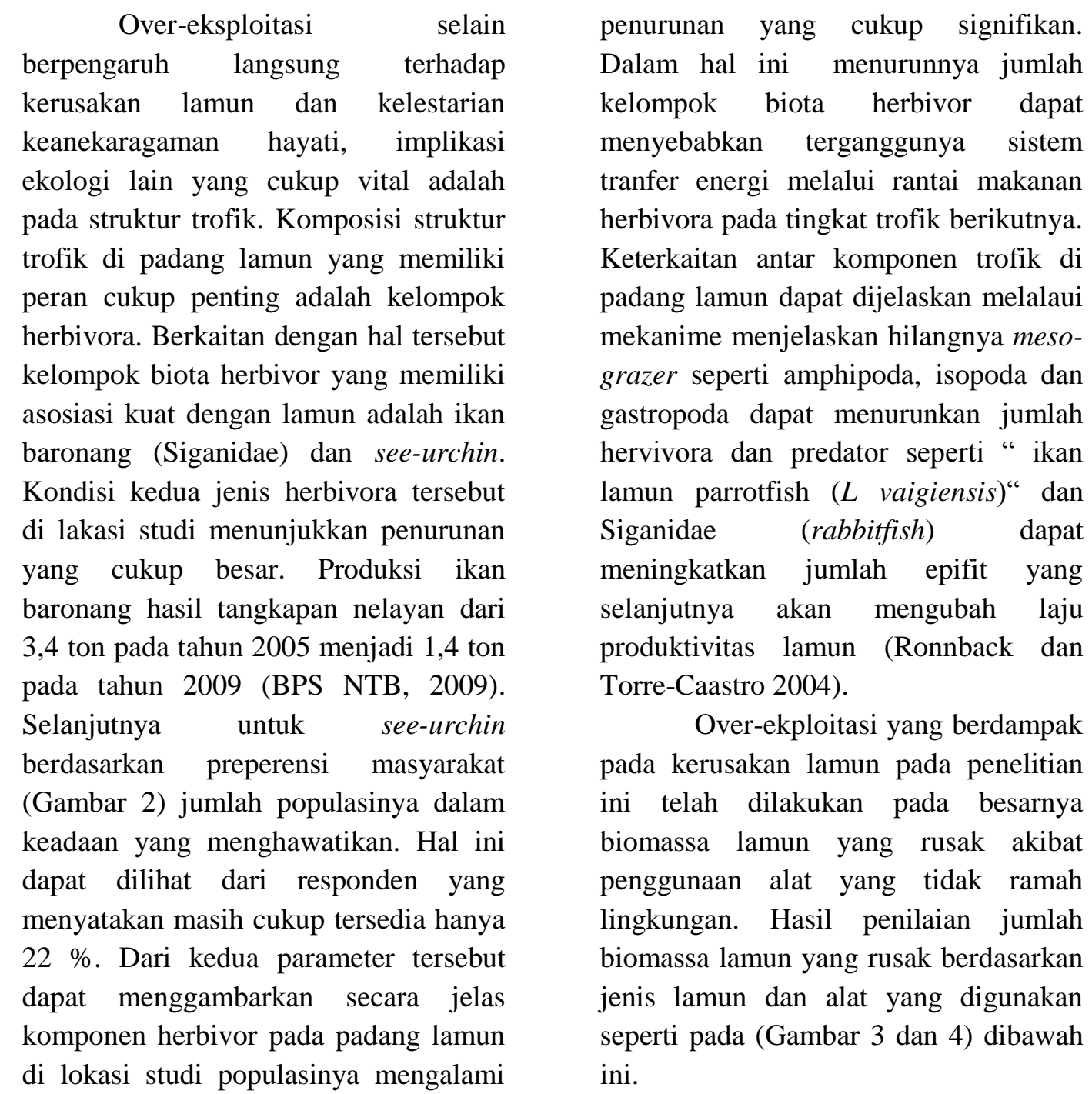

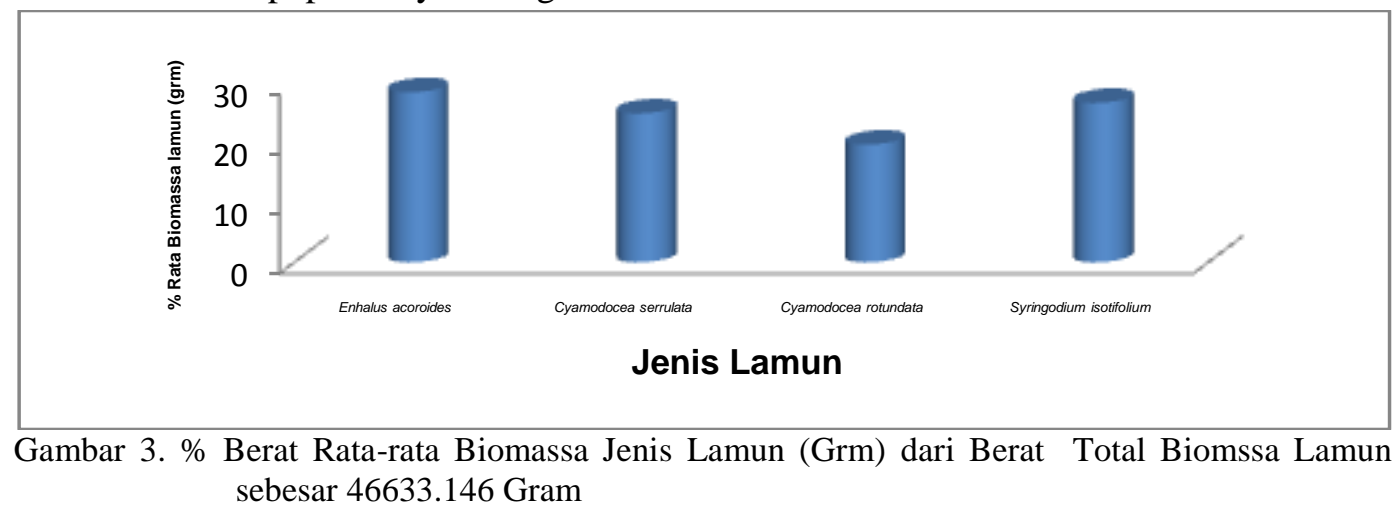




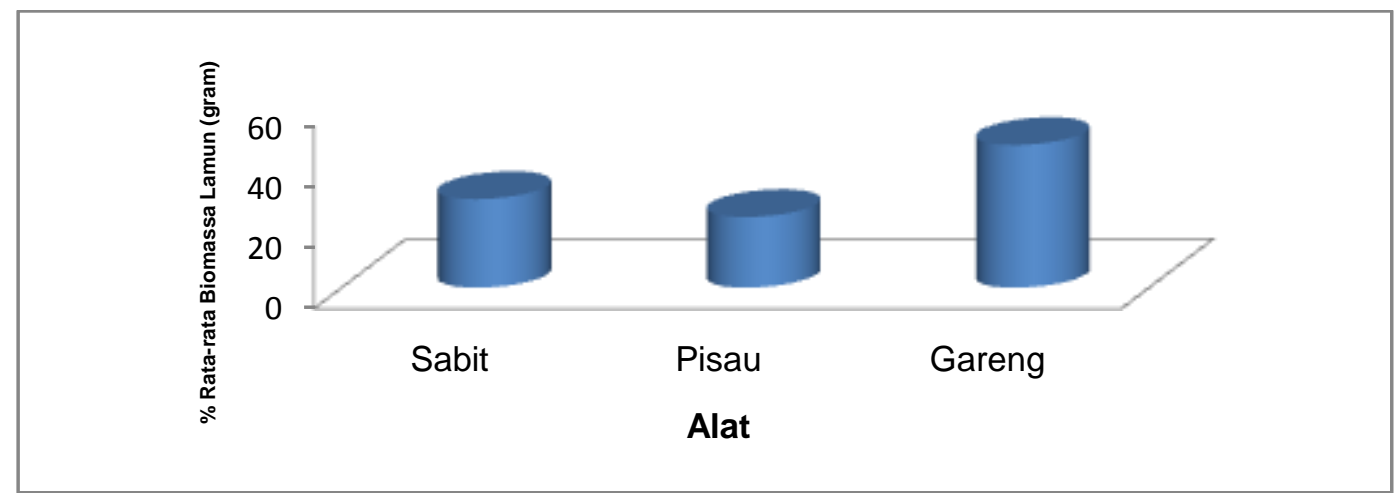

Gambar 4. \% Berat Rata-rata Biomassa (Grm) dari Sabit, Pisau dan Gareng dari Berat Total Biomssa Lamun sebesar 46633.146 Gram

Nilai biomassa lamun (Gambar 3 dan 4) diperoleh melalui survei saat masyarakat memanfaatkan air surut untuk mencari jenis biota yang bernilai konsumsi. Penilaian tersebut bertujuan untuk memahami secara lebih spesifik dampak over-ekploitasi terhadap kerusakan lamun. Implikasi ekologi dari kerusakan lamun akibat pemanfaatan yang tidak ramah lingkungan tersebut adalah menurunnya produkstivitas lamun sebagai produsen primer. Kondisi ini pada skala yang lebih luas dapat berpengaruh negatif secara ekologi terutama terhadap fungsi lamun dalam menjaga keseimbanagan pertukaran gas $\mathrm{CO}_{2}$ dan $\mathrm{O}_{2}$ melalui makanisme fotosintesisnya. Disisi lain biomassa lamun merupakan indikator yang cukup relevan dan signifikan secara ekologi sebagai alat monitoring untuk mencapai tujuan konservasi atau perlindungan lamun. Pooler et al (2011) menyatakan biomassa lamun dapat sebagai indikator pada tingkat yang lebih tinggi dari atribut lamun yang lain seperti kepadatan, penutupan dan kelimphan sebagai alat monitoring untuk mencapai tujuan konservasi.

\section{Rumusan Konservasi}

Over-ekploitasi yang telah berdampak pada penurunan jumlah populasi biota secara signifikan terutama pada biota yang bernilai ekonomi dan kerusakan lamun. Implikasi ekologi seperti yang telah dijelaskan sebelumnya dapat menggambarkan tingginya ancaman lamun di lokasi studi. Kerusakan lamun akibat over-ekploitasi telah menjadi isu penting, selain fungsi lamun yang memiliki produktivitas tinggi dan mendukung keanekaraman ikan di terumbu karanag di perairan Pasifik (Cullen dan Unsworth 2010). Selanjutnya dijelaskan kedua parameter tersebut sebagai argumentasi yang rasional untuk mencapai konsensus untuk melakukan konservasi terhadap lamun.

Lamun sebagai sasaran konservasi memiliki atribut yang cukup luas. Namun pada penelitian ini atribut lamun yang digunakan sebagai indikator dalam rumusan konservasi meliputi pertama implikasi ekologi akibat overekploitasi baik oleh nelayan maupun masyarakat non nelayan. Indikator tersebut adalah yang berhubungan dengan nilai keragaman biota yang 
diperoleh dari lokasi padang lamun yang memiliki nilai ekonomi. Dalam hal ini adalah kelestarian keanekaragaman hayati dan penurunan populasi dari komponen penyusun struktur trofik yaitu kelompok herbivor. Kedua adalah nilai biomasa lamun yang rusak akibat pengamabilan jenis biota dari areal lamun dengan cara tidak ramah lingkungan. Rumusan indikator konservasi lamun dari kedua parameter tersebut seperti pada (Tabel 3) di bawah ini.

Tabel 3. Rumusan Indikator dan Urairan Indikator Konservasi Lamun di Lokasi Studi.

\begin{tabular}{|c|c|c|c|}
\hline No & Indikator & Uraian Indikator & Fungsi \\
\hline 1 & Biodiversity & $\begin{array}{l}\text { 1. Eksploitasi yang tidak terkontrol dari } \\
\text { keragaman bentuk pemanfaatan telah } \\
\text { berdampak negatif terhadap biota } \\
\text { laut di padang lamun seperti ikan, } \\
\text { tripang, kepiting, moluska dan see- } \\
\text { urchin. } \\
\text { 2. Kelestarian biodiversity berada pada } \\
\text { tingkat yang sangat } \\
\text { mengahawatirkan }\end{array}$ & $\begin{array}{l}\text { 1. Penilaian perubahan biota } \\
\text { laut sebagai sasaran dari } \\
\text { keragaman bentuk } \\
\text { pemanfaatan } \\
\text { 2. Informasi penting yang } \\
\text { dapat menggambarkan } \\
\text { keterkaitan masyarakat } \\
\text { dengan padang lamun } \\
\text { 3. Dasar konservasi atau } \\
\text { perlindungan berbasis } \\
\text { ekosistem }\end{array}$ \\
\hline 2 & Struktur trofik & $\begin{array}{l}\text { 1. Turunnya jumlah ikan herbivora } \\
\text { yang cukup signifikan dari ikan } \\
\text { baronang yaitu } 3,4 \text { ton pada tahun } \\
2005 \text { menjadi } 1,4 \text { ton tahun } 2009 \text { dan } \\
\text { biota lain seperti see-urchin } \\
\text { 2. Pemindahan biomassa pada beberapa } \\
\text { level trofik (herbivora, invvertivora, } \\
\text { karnivora dan omnivora) secara } \\
\text { tidak terkontrol dari nelayan dan } \\
\text { masyarakat dapat mempengaruhi } \\
\text { komposisi struktur trofik pada sistem } \\
\text { ekologi laut. }\end{array}$ & $\begin{array}{l}\text { 1. Penilaian perubahan hasil } \\
\text { yang diperoleh dari } \\
\text { keragaman bentuk } \\
\text { pemanfaatan dari lokasi } \\
\text { padang lamun } \\
\text { 2. Dasar konservasi pada } \\
\text { level spesies dan } \\
\text { ekosistem }\end{array}$ \\
\hline 3 & $\begin{array}{l}\text { Pertumbuhan } \\
\text { dan } \\
\text { produktivitas } \\
\text { lamun }\end{array}$ & $\begin{array}{l}\text { 1. Jumlah rata-rata biomassa lamun } \\
\text { (gram berat basah/hari) dalam satu } \\
\text { periode pasut tiap bulan yang lepas } \\
\text { sebelum waktunya dari cara } \\
\text { pemanfaatan yang tidak ramah } \\
\text { lingkungan } \\
\text { 2. Jumlah individu } / \mathrm{m}^{2} \text { dapat menurun } \\
\text { secara signifikan terutama pada areal } \\
\text { yang dimanfaatan secara intensif } \\
\text { yaitu pada areal banyak ditemukan } \\
\text { Cyamodocea serrulata dan Enhalus } \\
\text { acoroides }\end{array}$ & $\begin{array}{l}\text { 1. Penilaian dampak cara } \\
\text { pemanfaatan yang tidak } \\
\text { ramah lingkungan } \\
\text { terhadap daya pulih } \\
\text { lamun } \\
\text { 2. } \begin{array}{l}\text { Dasar perlindungan dan } \\
\text { konservasi lamun }\end{array}\end{array}$ \\
\hline
\end{tabular}




\section{Kesimpulan}

Lamun memiliki fungsi yang cukup vital dari aspek ekologi dalam mendukung kelestarian keanekaragaman hayati dan produktivitas primernya. Namun demikian ancaman kerusakan lamun akibat over-ekploitasi dapat menyebabkan fungsi lamun mengalami proses degradasi terutama sebagai pendukung keanekaragaman hayati dan proses tranfer energi melalui rantani makanan herbivora, serta berkurangnya produktivitas lamun akibat hilangnya biomassa lamun akibat cara pemanfaatan yang tidak ramah lingkungan, Oleh karena itu solusi untuk mengembalikan fungsi lamun tersebut adalah melalui konservasi.

\section{DAFTAR PUSTAKA}

Badan Pusat Statistik. 2009. Statistik Propinsi Nusa Tenggara Barat . Mataram NTB.

Coleman FC dan Williams SL. 2002. Overexploiting Marine Ecosystem Engineers Potential Consequences for Biodiversity. Trands Ecol Evol. Vol 17. 40 - 44.

Carlos MD, Maria LC, Cristina B, Jason AH dan Thomas KF. 2008. Ligh Regulation of Benthic Sulfate Reduction Rates Mediated by Seagrass (Thalassia testudinum) Metabolism. Journal Estuaries and Coasts. Vol. 29. 1255 - 1264.

Co-Fish Project 2001. Resources Environmental Assessmen (REA). Laporan. Pengelolaan Rencana Perikanan secara Partisipatif di Wilayah Pesisir dan Laut Kabupatanen Lombok Timur. Selong Lombok Timur Nusa Tenggara Barat.

Culen L C dan Unsworth R. K.F. 2010. Recognising the Necessity for Indo-Pacific Seagrass Conservation. Mini-Review. 1 -11 .

Dahuri R. 2003. Keanekaragaman Hayati Laut: Aset pembangunan berkelanjutan Indonesia. PT Gramedia Pustaka Utama. Jakarta. 38-52.

Davis AR. dan Fyfe SK. 2007. Spatial Scala and the Detection of Impacts on the Seagrass Posidonia australis Following Pier Construction in an Embayment in Southeastern Australia. Estuarine Coastal and Shelf Science. Vol 74. $297-305$. 
Funnel G, Turner SJ, Thrush SF, Hewitt JE dan Cummings VJ. 1999. Fishing Impacts and the Degradation or Loss of Habitat Structure. Fisheries Management and Ecology. Vol 6. $401-420$.

Griffiths S.P. 2001. Diel Variation in the Seagrass Ichthyofaunas of Three Intermittently Open Estuaries in South-Eastern Australia: Implications for Improving Fish Diversty Assessments. Fisheries Management and Ecology. Vol 8. $123-140$.

Larkum AWD. Robert JO dan Carlos M. Duarte. 2006. Seagrasses :

Biology, Ecology and Conservation. Springer. Netherlands.

Lavery P, Walker D I, Hilman K A and Kendrick G.A. 2001. Ecological Significance of Seagrass: Asessment for Management of Environmental Inpact in Western Australia. Ecological Enginnering. Vol 16. 323-330.

Mangi SC dan Roberts CM. 2007. Factors Influencing Fish Cath Level on Kenya's Coral Reef. Fish Manage Ecol. Vol 14. 245 253.

Neckless HA dan Frederick TS. 1999. The Effects of Global Climate Change on Seagrass. Aquatic Botani. Vol 63. 169 - 196. USA. Elsevier.

Nemeth DJ dan Jered BJ. 2007. A New Method to Describe Seagrass Habitat Sampled During Fisheries-Independent
Monitoring. Estuaries and Coasts. Vol 30. 171 - 178.

Pooler P S, Neekles H A, Kopp B S dan Peterson B J. 2011. Integreting Scales of Seagrass Monitoring to Meet Conservation Needs. Coastal and Estuarine Reseach Federation (USA ). Springer.

Ronnback P dan Torre-Castro M. de la. 2004. Links Between Humans and Seagrasses an Example From Tropical East Africa, Ocean \& Coastal Management. Vol. 47. 361 387.

Tomascik TAJ. Mah, A Nontji dan Moosa MK. 1997. The Ecology of the Indonesien seas. P. In the Republic of Singapore.

Unsworth RKF, De Leon PS, Garrad SL, Jompa J, Smith DJ dan Bell JJ. 2008. High Connectivity of IndoFasifik Seagrass Fish Assemblages with Mangrove and Coral Reef Habitats. Mar Ecol Prog Ser. Vol. 353. 213-224.

Unsworth RKF, Taylor JD, Bell JJ dan Smith DJ. 2007. The Contribution of Parrotfish (Scarid) Herbivory to Seagrass Ecosystem Dynamic in the IndoPasific. Estuar Coas Shelf Sci. Vol. $70.53-66$.

Waycott M, Hubes A R, Williams S L, Duarte C M dan Jr Heck K L. 2009. Assosiations of Concern: Declining Seagrass and Threatened Dependent Spesies. Fornt Ecol Environmental. Vol. 7 (5). $242-246$. 